\title{
ANALISIS PERBANDINGAN MODEL COST231-HATTA DAN WALFISCH IKEGAMI SEBAGAI FORMULA LINK BUDGET PADA LINTAS KOMUNIKASI DOWN LINK BASE STATION
}

\author{
Aisah, Moh. A. Anshori, Kristina Widjayanti, Ahmad Nur Siswanto \\ Jurusan Teknik Elektro, Politeknik Negeri Malang \\ aisahzahra@gmail.com, anshori_ma@yahoo.com,kristina@polinema.ac.id,ahmadnursiswanto@gmail.com \\ (Artikel diterima: Februari 2020, direvisi: April 2020, diterima untuk terbit: Juli 2020)
}

\begin{abstract}
Abstrak - Analisis perhitungan dan pengukuran untuk membandingkan Model Okumura-Hatta, Cost231-Hatta dan Walfisch Ikegami sebagai formula link budget pada lintas komunikasi down link base station, perhitungan menggunakan data dari salah satu operator di Indonesia wilayah Malang. Hasil penelitian dapat digunakan sebagai suatu masukan atau rekomendasi bagi operator seluler/vendor sebagai bahan pertimbangan bagi operator menggunakan formula link budget untuk memprediksi rugi-rugi propagasi yang tepat dengan teknologi yang digunakan dan disesuaikan dengan morfologi. Parameter yang dianalisis adalah radius sel sebagai jarak maksimal yang dapat dijangkau oleh base station. Perbandingan nilai radius sel hasil perhitungan dan pengukuran dianalisis untuk mengetahui hasil yang mendekati dengan nilai yang sebenarnya. Perhitungan link budget coverage area menggunakan 3 model, yaitul Okumura-Hatta untuk menghitung coverage area sistem GSM, Cost-231 Hatta untuk sistem DCS, dan Walfisch Ikegami untuk sistem UMTS 2100. Pengukuran menggunakan drive test untuk mengukur level daya sinyal yang dipancarkan oleh base station. Hasil drive test diperoleh nilai radius sel terjauh adalah $980 \mathrm{~m}$ dan nilai level daya sebesar $-91 \mathrm{dBm}$, sedangkan hasil perhitungan nilai radius sel nilai yang mendekati dengan nilai pengukuran adalah model Walfisch Ikegami nilai radius sel sebesar 1,06 km dan 1,05 km dan nilai level daya sebesar $90 \mathrm{dBm}$.
\end{abstract}

Kata kunci: jumlah, kata, kunci, minimal, lima, kata.

\section{Pendahuluan}

Terdapat banyak model formula link budget yang digunakan untuk memprediksi radius sel dan level daya terima, namun dalam penelitian tersebut akan dibandingkan dua formula link budget yaitu model Cost231-Hatta dan Walfisch Ikegami, karena pada kedua formula tersebut terdapat kesamaan range frekuensi kerja, hasil perhitungan dan pengukuran dibandingkan nilai radius sel dan level daya terima. Teknologi yang digunakan meliputi sistem GSM 900, DCS 1800 dan UMTS 2100. Link budget adalah formula yang digunakan untuk menghitung coverage area suatu base station untuk memprediksi rugi-rugi propagasi yang terdapat di ruang bebas, parameter yang dihitung adalah nilai radius sel sebagai jarak jangkauan maksimal daya pancar base station. Hasil perhitungan tersebut dibandingkan dengan hasil pengukuran, kemudian dianalisis nilai radius sel yang mendekati dengan nilai yang sebenarnya.

\section{A. Rumusan Masalah}

Rumusan masalah yang digunakan untuk penelitian adalah sebagai berikut:

- Perhitungan coverage area pada sistem GSM 900 menggunakan model Okumura-Hatta?

- Perhitungan coverage area pada sistem DCS 1800 menggunakan model Cost231-Hatta?

- Perhitungan coverage area pada UMTS 2100 menggunakan model Walfisch Ikegami?

- Perbandingan nilai radius sel hasil perhitungan model Cost231-Hatta dan Walfisch Ikegami Walfisch Ikegami? perbandingan hasil perhitungan link budget menggunakan formula model Okumura-Hatta, Cost231-Hatta dan Walfisch Ikegami. Analisis perbandingan hasil perhitungan kemudian dilakukan pengukuran untuk mengetahui hasil yang mendekati dengan nilai yang sebenarnya.

\section{Tinjauan Pustaka}

\section{A. Coverage Area}

Coverage area merupakan cakupan area yang dijangkau dari daya pancar antena base station (BS). BS biasanya terdiri dari 3 sektor sel untuk mencakup area $360^{\circ}$. Sebuah sel dapat didefinisikan sebagai daerah cakupan radio dari satu sistem antena BS. Sel adalah blok area terkecil dalam jaringan mobile yang dicover oleh BS. Sel digambarkan dalam bentuk segi enam (hexagonal). Terdapat 2 jenis daya pancar BS yaitu omnicell dan sectorcell. ${ }^{[15]}$

\section{B. Okumura Hatta}

Parameter yang digunakan untuk model OkumuraHatta, yaitu: frekuensi (f), distance (d), tinggi antena base station (hb) dan tinggi antena mobile station (hm). Persamaan (1) adalah untuk menentukan rugi-rugi propagasi morfologi urban. ${ }^{[7]}$

\section{Morfologi urban:}

$$
\begin{aligned}
L_{50}= & 69,55+26,16 \log f_{c}-13,82 \log h_{b}-a h_{m}+ \\
& \left(44,9-6,55 \log h_{b}\right) \log d \quad(1)
\end{aligned}
$$

Parameter untuk model Okumura-Hata adalah: $150 \mathrm{MHz} \leq$ $f_{c} \leq 1500 \mathrm{MHz}$

Tujuan penelitian adalah untuk melakukan analisis 
$30 \mathrm{~m} \leq h_{b} \leq 200 \mathrm{~m}$

$1 \mathrm{~m} \leq h_{m} \leq 10 \mathrm{~m}$

$1 \mathrm{~km} \leq \mathrm{d} \leq 20 \mathrm{~km}$

$a h_{m}$ dihitung berdasarkan:

a) Area kota kecil atau medium $a h_{m}=\left(1,1 \log f_{c}-0,7\right) h_{m}-\left(1,56 \log f_{c}-0,8\right)$

b) Area Sub Urban: $\mathrm{L}_{S U}=L_{50}-2\left[\log \left(\frac{f_{c}}{28}\right)\right]^{2}-5,4$

c) Area Open atau Rural: $L=L_{U}-4,78\left(\log f_{c}\right)^{2}+18,33 \log f_{c}-40,98$

\section{COST-231 Hatta}

Persamaan (2) adalah untuk model COST-231 Hata adalah:

$\mathrm{Lu}=46.3+33.9 \log f c-13.82 \log h b-a(h m)+(44.9-$ $6.55 \log h b) \log d+C M(2)$

Faktor koreksi tinggi antena MS, a(hm) sama dengan Hata Model dan centers metropolitan (CM).

Keterangan:

$1500 \leq \mathrm{fC} \leq 2000 \mathrm{MHz}$

$30 \leq \mathrm{ht} \leq 200 \mathrm{~m}$

$1 \mathrm{~m} \leq \mathrm{hr} \leq 10 \mathrm{~m}$

$1 \mathrm{~km} \leq \mathrm{d} \leq 20 \mathrm{~km}$

$\mathrm{a}(\mathrm{hm})$ adalah faktor koreksi antena mobile.

$$
\begin{gathered}
a(h m)= \\
d B
\end{gathered}
$$

\section{Walfisch Ikegami}

Model Wallfisch-Ikegami terdiri dari 3 parameter:

1) Free space loss $\left(\mathrm{L}_{\mathrm{f}}\right)$

2) Roof to street diffraction and scatter loss ( $\left.\mathrm{L}_{\mathrm{rts}}\right)$

3) Multiscreen loss ( $\left.\mathrm{L}_{\mathrm{ms}}\right)$

$$
\begin{aligned}
& \mathrm{L}_{50}=\mathrm{L}_{\mathrm{f}}+\mathrm{L}_{\mathrm{rts}}+\mathrm{L}_{\text {msd }} \text { Atau } \\
& \mathrm{L}_{50}=\mathrm{L}_{\mathrm{f}} \text { jika } \mathrm{L}_{\text {rts }}+\mathrm{L}_{\text {msd }} \leq 0
\end{aligned}
$$

Keterangan:

$$
\begin{aligned}
& \mathrm{L}_{\mathrm{f}}=\text { free space loss } \\
& \mathrm{L}_{\mathrm{rts}}=\text { roof to street diffraction and scatter loss } \\
& \mathrm{L}_{\mathrm{msd}}=\text { multiscreen loss }
\end{aligned}
$$

Path Loss (L50), yaitu:

$$
\mathrm{L}_{50}=\mathrm{L}_{\mathrm{f}}+\mathrm{L}_{b s h}+\mathrm{L}_{\mathrm{msd}} \quad \mathrm{dB}
$$

Free space loss $\left(\mathrm{L}_{\mathrm{f}}\right)$, yaitu:

$$
\mathrm{L}_{\mathrm{f}}=32.4+20 \log \mathrm{r}+20 \log \mathrm{f}_{\mathrm{c}} \mathrm{dB}
$$

Roof to street diffraction and scatter loss ( $\left.\mathrm{L}_{\mathrm{rts}}\right)$, yaitu:

$\mathrm{L}_{\mathrm{rts}}=-16.9-10 \log _{10} \mathrm{~W}+10 \log \mathrm{f}+20 \log _{10} \Delta \mathrm{hm}$

$$
+ \text { Lori dB }
$$

Keterangan:

$$
\mathrm{w}=\text { lebar jalan }(\mathrm{m}) \text {, dan }
$$

$\Delta \mathrm{h}_{\mathrm{m}}=\mathrm{h}_{\mathrm{r}}-\mathrm{h}_{\mathrm{m}} \quad(\mathrm{m})$.

$$
\begin{aligned}
& \mathrm{L}_{0}=-10+0,354(\phi) ; \quad 0^{0} \leq \phi \leq 35^{0} \\
& \mathrm{~L}_{0}=2,5+0,075(\phi-35) ; 35^{0} \leq \phi \leq 55^{0} \\
& \mathrm{~L}_{0}=4,0-0,114(\phi-55) ; 55^{0} \leq \phi \leq 90^{0}
\end{aligned}
$$

Keterangan:

$$
\phi=\text { sudut datang relatif terhadap jalan. }
$$

Multiscreen loss (Lmsd), yaitu: Keterangan:

$$
\mathrm{L}_{\mathrm{msd}}=\mathrm{Lbsh}_{\mathrm{b}}+\mathrm{k}_{\mathrm{a}}+\mathrm{k}_{\mathrm{d}} \log _{10} \mathrm{r}+\mathrm{kf}_{\mathrm{f}} \log _{10} \mathrm{f}_{\mathrm{c}}-9 \log _{10} \mathrm{~b}
$$

$\mathrm{b}=$ jarak antar gedung sepanjang lintasan radio (m)

$0 \quad ; \mathrm{h}_{\mathrm{b}}<\mathrm{h}_{\mathrm{r}}$

$\mathrm{L}_{\mathrm{bsh}}=-18 \log \left(1+\Delta \mathrm{h}_{\mathrm{b}}\right) \quad ; \mathrm{h}_{\mathrm{b}}>\mathrm{h}_{\mathrm{r},} \quad \mathrm{L}_{\mathrm{bsh}}=$

$\mathrm{k}_{\mathrm{a}}=54 \quad ; \mathrm{h}_{\mathrm{b}}>\mathrm{h}_{\mathrm{r}}$,

$\mathrm{k}_{\mathrm{a}}=54-0,8 \mathrm{~h}_{\mathrm{b}} ; \mathrm{r} \geq 500 \mathrm{~m}, \mathrm{~h}_{\mathrm{b}}<\mathrm{h}_{\mathrm{r}, \mathrm{k}_{\mathrm{a}}=54}$

$1,6 \Delta \mathrm{h}_{\mathrm{b}} . \mathrm{r} ; \mathrm{r}<500 \mathrm{~m}, \mathrm{~h}_{\mathrm{b}}<\mathrm{h}_{\mathrm{r}}$,

$\mathrm{k}_{\mathrm{d}}=18 \quad ; \mathrm{h}_{\mathrm{b}}>\mathrm{h}_{\mathrm{r}}$,

$\mathrm{k}_{\mathrm{d}}=18-15\left(\Delta \mathrm{h}_{\mathrm{b}} / \mathrm{h}_{\mathrm{r}}\right) ; \mathrm{h}_{\mathrm{b}} \leq \mathrm{h}_{\mathrm{r}}$

$\mathrm{k}_{\mathrm{f}}=-4+0,7\left(\mathrm{f}_{\mathrm{c}} / 925-1\right)$; urban suburban

$\mathrm{k}_{\mathrm{f}}=-4+1.5\left(\mathrm{f}_{\mathrm{c}} / 925-1\right) ;$ metropolitan.

Parameter model Wallfisch-Ikegami adalah:

$800 \mathrm{MHZ} \leq \mathrm{f}_{\mathrm{c}} \leq 2000 \mathrm{MHz}$

$4 \mathrm{~m} \leq \mathrm{h}_{\mathrm{b}} \leq 50(\mathrm{~m})$

$1 \mathrm{~m} \leq \mathrm{h}_{\mathrm{m}} \leq 3(\mathrm{~m})$

$0,02 \mathrm{~km} \leq \mathrm{r} \leq 5(\mathrm{~km})$

\section{Metode Penelitian}

Metode penelitian analisis Perbandingan model Cost231-Hatta dan Walfisch Ikegami Sebagai Formula Link Budget Pada Lintas Komunikasi Downlink Base Station, dimulai dengan tinjauan pustaka tentang peneliti sebelumnya yang berkaitan dengan penelitian yang dilakukan, teori tentang teknologi sistem GSM/DCS dan UMTS, penentuan formula link budget coverage area suatu base station model Okumura-Hatta, COST-231 Hatta dan Walfisch Ikegami, penentuan parameter-parameter sistem GSM/DCS dan UMTS, survei dan pengumpulan data untuk link budget, perhitungan link budget untuk memperoleh nilai radius sel pada suatu BS, analisis hasil perhitungan link budget, perbandingan pada model formula link budget yang berbeda, perbedaan nilai radius sel dianalisis kemudian dilanjutkan pengukuran drive test menggunakan TEMS. Perbandingan nilai radius sel hasil perhitungan coverage area menggunakan formula link budget dan mengukur coverage area drive test menggunakan TEMS. Hasil analisis kemudian disimpulkan nilai radius sel yang mendekati dengan nilai yang sebenarnya. Gambar 1 adalah proses plot coverage area site BS. 


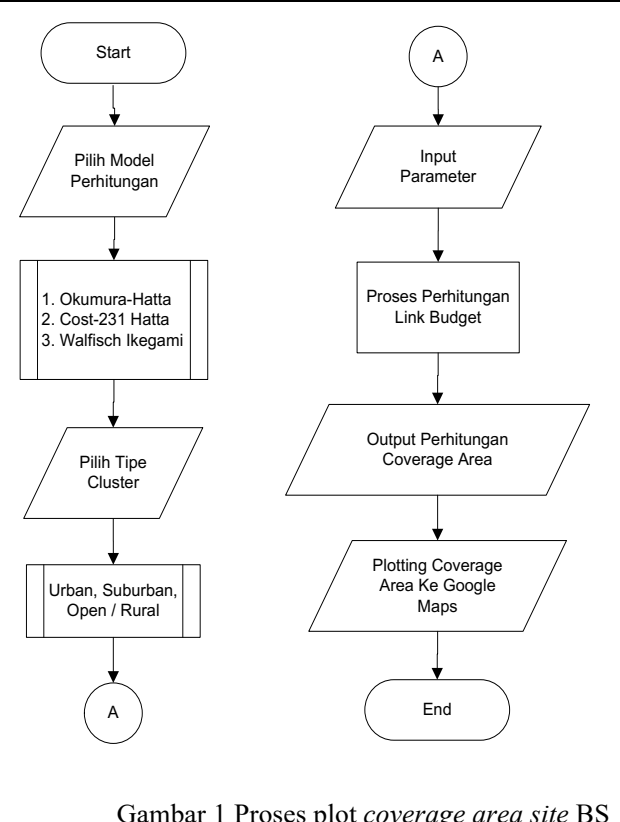

Gambar 1 menunjukkan bahwa untuk menggambarkan radius sel pada masing-masing teknologi yaitu memilih jenis model link budget yang digunakan, pemilihan jenis morfologi area layanan yaitu urban dan suburban, menentukan parameter-parameter yang dihitung, perhitungan nilai radius sel menggunakan formula link budget coverage area, menampilkan hasil nilai radius sel, plot nilai radius sel menggunakan peta google maps dengan memasukkan data koordinat site longitude dan latitude.

\section{Hasil Dan Pembahasan}

Tabel 1 adalah hasil perhitungan coverage area 30 site base station wilayah kota Malang morfologi urban. Perhitungan coverage area GSM 900 menggunakan model Okumura-Hatta, sistem DCS menggunakan Model COST231 Hatta, sistem UMTS2100 menggunakan Model Walfisch Ikegami. Berdasarkan hasil perhitungan dalam Tabel 1 menunjukkan bahwa nilai radius sel yang diperoleh dari 30 site base station dengan morfologi urban pada sistem GSM 900, DCS 1800 dan UMTS2100 berdasarkan frekuensi kerja semakin tinggi frekuensi maka nilai radius sel semakin kecil, yaitu pada sistem UMTS2100

Hasil perhitungan coverage area pada sistem GSM 900 menggunakan model Okumura diperoleh nilai radius sel pada 30 site wilayah Malang adalah rata-rata $1,642 \mathrm{~km}$, nilai radius sel terkecil pada site Ketawang-gede adalah $1,13 \mathrm{~km}$ dan radius sel terbesar pada site ITN adalah $2,14 \mathrm{~km}$.

Hasil perhitungan coverage area pada sistem DCS 1800 menggunakan model Cost-231 Hatta diperoleh nilai radius sel pada 30 site wilayah Malang adalah rata-rata $1,08533 \mathrm{~km}$, nilai radius sel terkecil pada site Ketawang-gede adalah 0,73 $\mathrm{km}$ dan nilai radius sel terbesar pada site ITN, Gadang dan Lowokwaru adalah $1,27 \mathrm{~km}$.

Hasil perhitungan coverage area pada sistem UMTS 2100 menggunakan model Walfisch Ikegami diperoleh nilai radius sel pada 30 site wilayah Malang adalah rata-rata $0,50133 \mathrm{~km}$. Nilai radius sel terkecil pada site Ketawanggede adalah $0,26 \mathrm{~km}$ dan nilai radius sel terbesar pada site ITN, Gadang dan Lowokwaru adalah 0,66 km.

Hasil perbandingan coverage area berdasarkan hasil perhitungan nilai radius sel diperoleh pada model Hatta Okumura nilai radius sel rata-rata sebesar $1.642 \mathrm{~m}$, Cost-231
Hatta nilai radius sel rata-rata sebesar $1.085,33 \mathrm{~m}$ dan Walfisch Ikegami nilai rata-rata sebesar $501,33 \mathrm{~m}$. Berdasarkan hasil tersebut nilai radius sel paling kecil adalah formula link budget model Walfisch Ikegami.

\begin{tabular}{|c|c|c|c|}
\hline Site Name & $\begin{array}{c}\text { Radius } \\
\text { sel } \\
\text { GSM900 } \\
(\mathrm{km})\end{array}$ & $\begin{array}{c}\text { Radius } \\
\text { sel DCS } \\
1800 \\
(\mathrm{~km})\end{array}$ & $\begin{array}{l}\text { Radius } \\
\text { sel } \\
\text { U2100 } \\
(\mathrm{km})\end{array}$ \\
\hline Blimbingim & 1,97 & 1,21 & 0,65 \\
\hline Diengmala & 1,69 & 1,05 & 0,54 \\
\hline Gajayana_Tbg & 1,4 & 0,89 & 0,41 \\
\hline Ketawanggd & 1,13 & 0.73 & 0,26 \\
\hline Puncaktdar & 1,91 & 1,18 & 0,63 \\
\hline Welirangtbg & 1,78 & 1,1 & 0,57 \\
\hline D2itn & 2,14 & 1,27 & 0,66 \\
\hline Gadang & 2,14 & 1,27 & 0,66 \\
\hline Gjayanamlg & 1,55 & 0,95 & 0,43 \\
\hline Kelayatan & 1,83 & 1,1 & 0,55 \\
\hline Lowokwaru & 2,14 & 1,27 & 0,66 \\
\hline Mergosono & 2,08 & 1,24 & 0,64 \\
\hline Tlogomas & 1,79 & 1,08 & 0,53 \\
\hline Barengmlg & 1,45 & 1,07 & 0,45 \\
\hline Brawijaya & 1,45 & 1,07 & 0,45 \\
\hline Citandui & 1,33 & 0,99 & 0,39 \\
\hline IKIPMLG & 1,55 & 1,14 & 0,49 \\
\hline KalpatarmLG & 1,63 & 1,2 & 0,53 \\
\hline Karanglo & 1,54 & 1,13 & 0,49 \\
\hline Kotalama & 1,44 & 1,06 & 0,44 \\
\hline $\begin{array}{c}\text { KSTRNMLGI } \\
\text { M3 }\end{array}$ & 1,58 & 1,17 & 0,51 \\
\hline MALANGMSC & 1,49 & 1,10 & 0,47 \\
\hline GITAFM & 1,64 & 1,2 & 0,48 \\
\hline STIEMALANG & 1,81 & 1,32 & 0,54 \\
\hline Santika Malang & 1,42 & 1,05 & 0,36 \\
\hline DMATOS & 1,42 & 1,05 & 0,38 \\
\hline Rayatidar & 1,6 & 1,18 & 0,52 \\
\hline Sawojajar & 1,45 & 1,07 & 0,45 \\
\hline Siguragura & 1,46 & 1,08 & 0,45 \\
\hline Sukrnohtim3 & 1,45 & 1,07 & 0,45 \\
\hline
\end{tabular}

Gambar 2 adalah hasil plotting coverage area untuk sistem GSM 900 wilayah kota malang menggunakan model Okumura-Hatta. 


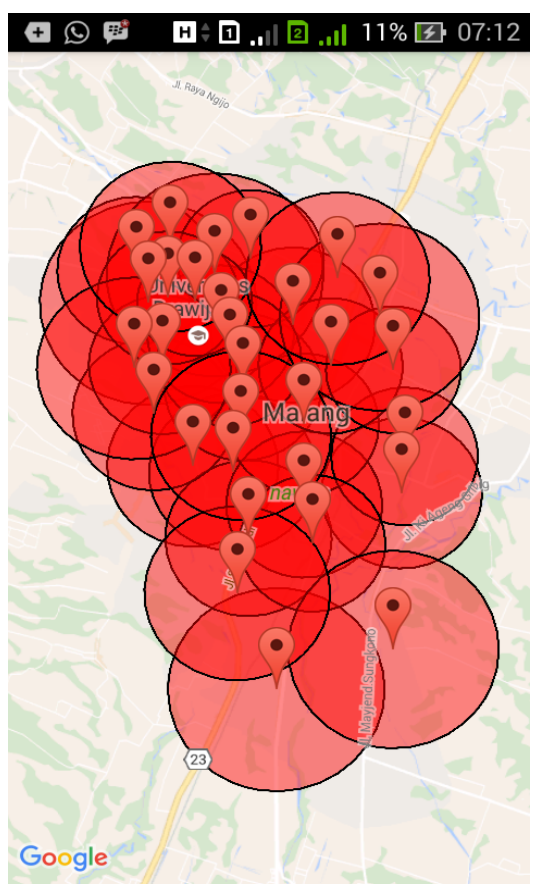

Gambar 2 Hasil plotting coverage area sistem GSM 900 menggunakan model Okumura-Hatta.

Gambar 3 adalah Hasil plotting coverage area sistem DCS 1800 wilayah kota Malang menggunakan model Cost231 Hatta.

Gambar 4 adalah Hasil plotting coverage area sistem UMTS 2100 wilayah kota Malang menggunakan model Walfisch Ikegami.

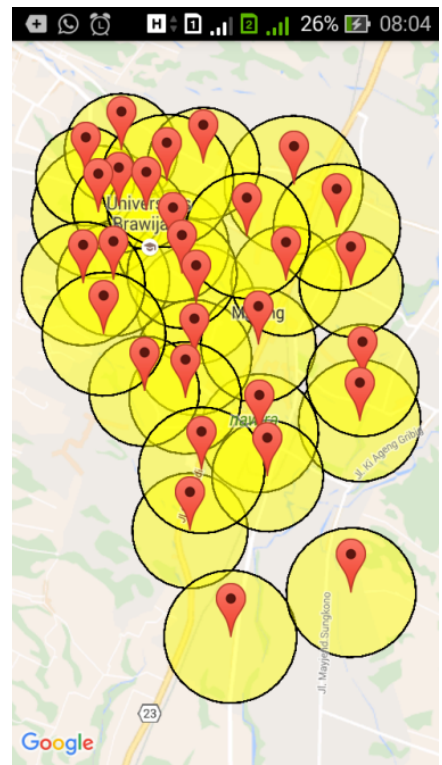

Gambar 3 Hasil plotting coverage area sistem DCS 1800 wilayah kota Malang
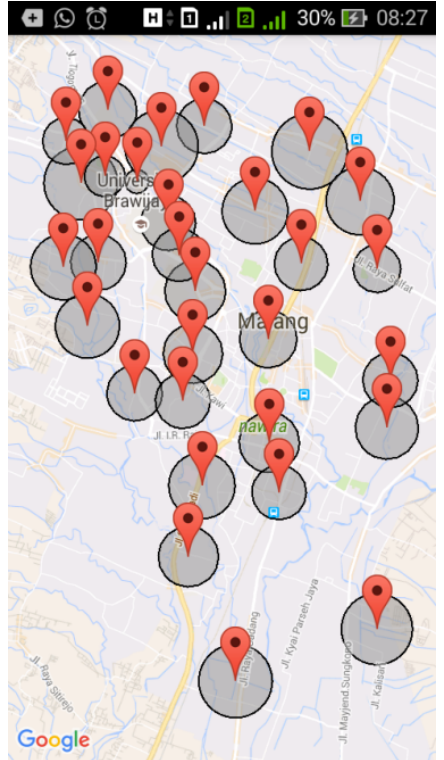

Gambar 4 adalah hasil plotting coverage area sistem UMTS 2100 wilayah kota Malang menggunakan model Walfisch Ikegami.

Coverage area suatu site diperoleh nilai radius sel. Nilai radius sel yang terkecil terdapat pada site Ketawang Gede yaitu $1.13 \mathrm{~km}$ untuk sistem GSM 900, $0.73 \mathrm{~km}$ untuk sistem DCS 1800, dan $0.26 \mathrm{~km}$ untuk sistem UMTS 2100, pada tinggi antena sektoral yang sama yaitu $13,5 \mathrm{~m}$. Sedangkan nilai radius sel yang terbesar terdapat pada site ITN dan Gadang yaitu 2.14 km untuk sistem GSM 900, $1.27 \mathrm{~km}$ untuk sistem DCS 1800, dan $0.66 \mathrm{~km}$ untuk sistem UMTS 2100, dengan tiinggi antena yang sama yaitu $53 \mathrm{~m}$.

Gambar 2, Gambar 3 dan Gambar 4 menunjukkan bahwa hasil perbandingan plotting coverage area pada google map. Tabel 1 menunjukkan bahwa hasil perhitungan formula model link budget coverage area menggunakan model Okumura Hatta terdapat selisih nilai radius sel \pm 30 m yang lebih besar dibandingkan menggunakan model Walfisch Ikegami. Faktor yang menyebabkan adalah terdapat parameter tambahan pada Walfisch Ikegami lebih detail yaitu parameter lebar jalan raya, tinggi rata-rata gedung, jarak antar bangunan. Sedangkan pada model Okumura Hatta hanya membutuhkan parameter rugi rugi propagasi pada lintasan dan perangkat trasnceiver BS. Model Okumura Hatta maupun Walfisch Ikegami merupakan sama-sama model empiris atau pendekatan. Penelitian melakukan analisis perbandingan terhadap formula tersebut sebagai formula link budget pada lintas komunikasi down link yaitu melakukan perhitungan dan pengukuran di ruang bebas. Hasil pengukuran drive test menggunakan TEMS di ruang bebas nilai radius sel pada tiap sektor jangkauan terjauh yaitu $980 \mathrm{~m}$ dengan nilai level daya sebesar $-91 \mathrm{dBm}$. Hasil perhitungan diperoleh nilai radius sel $1,06 \mathrm{~km}$ dan $1,05 \mathrm{~km}$ dengan nilai level daya sebesar -90 $\mathrm{dBm}$, selisih antara hasil perhitungan dan pengukuran yaitu kurang dari $100 \mathrm{~m}$, ditunjukkan pada model Walfisch Ikegami.

\section{Penutup}

Berdasarkan hasil perhitungan, pengukuran dan analisis, 
dapat disimpulkan sebagai berikut:

- Hasil perhitungan coverage area pada sistem GSM 900 menggunakan model Okumura diperoleh nilai radius sel pada 30 site wilayah Malang adalah rata-rata 1,642 km, nilai radius sel terkecil pada site Ketawang-gede adalah $1,13 \mathrm{~km}$ dan radius sel terbesar pada site ITN adalah 2,14 $\mathrm{km}$.

- Hasil perhitungan coverage area pada sistem DCS 1800 menggunakan model Cost-231 Hatta diperoleh nilai radius sel pada 30 site wilayah Malang adalah rata-rata $1,08533 \mathrm{~km}$, nilai radius sel terkecil pada site Ketawanggede adalah $0,73 \mathrm{~km}$ dan nilai radius sel terbesar pada site ITN, Gadang dan Lowokwaru adalah 1,27 km.

- Hasil perhitungan coverage area pada sistem UMTS 2100 menggunakan model Walfisch Ikegami diperoleh nilai radius sel pada 30 site wilayah Malang adalah ratarata $0,50133 \mathrm{~km}$. Nilai radius sel terkecil pada site Ketawang-gede adalah $0,26 \mathrm{~km}$ dan nilai radius sel terbesar pada site ITN, Gadang dan Lowokwaru adalah $0,66 \mathrm{~km}$.

- Hasil perbandingan coverage area berdasarkan hasil perhitungan nilai radius sel diperoleh pada model Hatta Okumura nilai radius sel rata-rata sebesar $1.642 \mathrm{~m}$, Cost231 Hatta nilai radius sel rata-rata sebesar $1.085,33 \mathrm{~m}$ dan Walfisch Ikegami nilai rata-rata sebesar 501,33 m. Berdasarkan hasil tersebut nilai radius sel paling kecil adalah formula link budget model Walfisch Ikegami.

- Hasil drive test diperoleh nilai radius sel paling jauh adalah $980 \mathrm{~m}$ dan nilai level daya sebesar $-91 \mathrm{dBm}$, sedangkan hasil perhitungan nilai radius sel yang mendekati dengan nilai pengukuran adalah model Walfisch Ikegami sebesar 1,06 km dan 1,05 km dan nilai level daya yang sama sebesar $-90 \mathrm{dBm}$.

\section{REFERENSI}

[1] Binsar D. Purba, "Simulasi Prediksi Cakupan Antena pada BS", Universitas Diponegoro, Semarang, 2011.

[2] Ratih Hikmah Puspita, "Perhitungan Link budget Pada Komunikasi GSM Di Daerah Urban Cluster Central Business Distric (Cbd), Residences, Dan Perkantoran”, PENS, Surabaya.

[3] Novredo Alfian, "Pembuatan Software Aplikasi Pemetaan Cell Coverage UMTS900 Untuk Modul Pembelajaran Praktikum Sistem Komunikasi Bergerak", Polinema, Malang, 2015.

[4] Ajay R Mishra, "Advanced Cellular Network Planning And Optimisation", Inggris, 2007.

[5] Harri Holma and Antti Toskala, "WCDMA for UMTS", Finlandia, 2004.

[6] Jukka Lempianinen and Matti Manninen, "UMRA Radio Network Planning, Optimization and QOS Management", USA, 2004

[7] Eraldo Damosso, "COST Action 231 Digital Mobile Radio Towards Future Generation Systems", European Commision, 1999.

[8] Nokia Siemens Network, "Introducing LTE with Maximum reuse of GSM assets", 2011.

[9] Reiner Stuhlfauth, Rohde \& Schwarz, "GSM Network Structure and Network Planning"

[10] Priyanta F, "Pemograman Android Untuk Pemula", Jakarta, 2011.

[11] Kevin Grant and Chris Haseman, "Beginning Android Programming: Develop and Design, 2014.

[12] Anas Amrullah Hidayat, "Penentuan Kualitas Jaringan CDMA 1xEVDO Rev.B Dengan Metode Drive test", Universitas Brawijaya, Malang, 2014.
[13] Chris Braithwaite and Mike Scott, "UMTS Network Planning and Development", Burlington, 2004.

[14] Fahmi Mahyudin, "Analisa Pengaruh Perubahan Tilting Antena Sektoral BTS Secara Electrical Dan Mechanical Terhadap Perolehan Sinyal MS Dan Kualitas Layanan", Universita Sumatra Utara, Medan, 2011.

[15] Aisah. ST., MT, dan M. Junus, ST., MT, "Modul Ajar Panduan Praktikum Sistem Komunikasi Bergerak", Polinema, Malang, 2011 